\title{
Criatividade no ensino médio segundo seus estudantes ${ }^{1}$
}

\author{
Janaina Maria Oliveira Almeida ${ }^{2}$ \\ Instituto de Ensino Superior Cenecista, Unai-MG, Brasil \\ Eunice Maria Lima Soriano de Alencar \\ Universidade Católica de Brasília, Brasília-DF, Brasil
}

\begin{abstract}
Resumo: O estudo examinou a percepção de alunos do ensino médio quanto ao nível de sua criatividade, de seus professores e colegas, bem como a extensão em que práticas docentes utilizadas por seus professores contemplavam a criatividade. Participaram do estudo 217 alunos de uma escola particular de ensino, os quais responderam uma escala de avaliação do nível de criatividade, uma questão aberta e um inventário de práticas docentes. Os resultados revelaram que os alunos avaliaramse como significativamente mais criativos do que seus professores e colegas, tendo ainda aproximadamente metade dos estudantes concordado total ou parcialmente que seus professores têm contemplado o desenvolvimento e a expressão do potencial criativo. Constatou-se também que os procedimentos pedagógicos com maiores médias foram estimular os alunos a analisar diferentes aspectos de um problema e levá-los a perceber pontos de vista divergentes sobre um tema em estudo.
\end{abstract}

Palavras-chave: criatividade, educação secundária, professores.

\section{Creativity in high school according to students}

\begin{abstract}
The study examined high school students` perception about their creativity level, their teachers and colleagues level of creativity as well as the extent to what their teachers' pedagogical practices contemplated creativity. The participants were 217 students from a private school. The instrument used for the data collection included a scale of evaluation of the level of creativity, one open question, and an inventory of pedagogical practices. The results revealed that the students evaluated themselves as significantly more creative than their teachers and colleagues. In addition, nearly half of the students agreed total or partially that their teachers have contemplated the development and the expression of the creative potential. The results also indicated that the teaching practices with higher means were stimulating students to analyze different aspects of a problem and leading them to realize the contrasting points of view about a topic of study.
\end{abstract}

Keywords: creativity, high school, teachers.

\section{La creatividad de la enseñanza secundaria de acuerdo a sus estudiantes}

\begin{abstract}
Resumen: El studio ha examinado la percepción de alumnos de la enseñanza secundaria cuanto al nivel de su creatividad, la creatividad de sus maestros y compañeros de clase, así como la extensión en cuales prácticas docentes utilizadas por sus maestros contemplaban la creatividade. Han participado del studio 217 alumnos de un colegio de enseñanza privada, los cuales han contestado a una sucesión de evalución del nivel de creatividad, una cuestión abierta y un inventario de prácticas docentes. Los resultados han revelado que los alumnos se evaluaron como significativamente más creativos que sus profesores y compañeros, teniendo aproximadamente la mitad de los estudiantes concordado total o parcialmente que sus profesores han logrado el desarollo y expression del potencial creativo. Se hizo atestiguar también que las tácticas pedagógicas con mayores éxitos fueron incitar los alumnos a investigar distintos aspectos de un obstáculo y llevarlos a juzgar temas distintos concernientes un tema en investigación.
\end{abstract}

Palabras clave: creatividad, enseñanza secundaria, profesores.

Criatividade é um fenômeno complexo e plurifacetado, que se manifesta em diferentes níveis e nos mais diversos campos da atividade humana. A sua importância tem sido apontada por políticos, sociólogos, educadores e outros profissionais, dadas as mudanças drásticas e inesperadas que ocorrem em curto espaço de tempo, requerendo do indivíduo não apenas conhecimento, mas também criatividade, iniciativa e flexibilidade.

\footnotetext{
${ }^{1}$ Este trabalho é derivado da Dissertação de Mestrado defendida pela primeira autora, sob a orientação da segunda, no Programa de Pós-graduação em Educação da Universidade Católica de Brasília.

${ }^{2}$ Endereço para correspondência:

Janaina Maria Oliveira Almeida. Rua Celina Lisboa Frederico, $\mathrm{n}^{\circ}$ 142, Centro, CEP 38.610-000. Unaí-MG, Brasil. E-mail: janaina@ unacabo.com.br
}

Não há definição precisa para o termo criatividade, embora vários autores concordem que a criatividade deva ser entendida como uma habilidade a ser aprimorada por meio da prática, capaz de trazer à tona algo novo ou realizado de forma diferente, com valor para um grupo significativo de pessoas (Alencar, 1996, 2001; Alencar \& Fleith, 2003a; Bono, 1994; Cheung, Rudowicz, Yue, \& Kwan, 2003; Feldman, Csikszentmihalyi, \& Gardner, 1994; Martínez, 1997). No que diz respeito à criatividade no trabalho pedagógico, esta é considerada como formas de se ensinar, de se educar, com algum tipo de novidade e que resulte em algo valioso para a aprendizagem e para o desenvolvimento dos alunos (Martínez, 2006).

Em consonância com o atual cenário de constantes mudanças, o mercado de trabalho tem exigido profissionais cada vez mais capazes de prever e identificar problemas novos, 
além de estarem aptos a propor soluções adequadas para resolvê-los. Por consequência, empresas se preocupam em contratar pessoas que se destaquem pela criatividade. Afinal, aquilo que funciona hoje poderá não funcionar amanhã.

Ante esta situação, é fundamental que na família, escola e sociedade, haja um aporte ao desenvolvimento e expressão do potencial criativo, de forma a propiciar ao indivíduo oportunidades de se tornar pró-ativo, buscar alternativas, novas ideias e novas maneiras de fazer as coisas.

Quintián (2006) considera a escola como o melhor contexto para propiciar o desenvolvimento da criatividade, cabendo-lhe fortalecê-la em níveis expressivos, por meio de um ambiente enriquecido de qualidade e intencionalidade neste campo. Isto significa compreender o indivíduo como protagonista e construtor da própria formação e aprendizagem, o professor como facilitador deste processo e o ambiente, como um entrelaçamento entre vivência, meio e interação ativa, de forma a instalar e provocar o ato criativo. No entanto, em geral, a escola ensina ao indivíduo formas de pensar e agir que impedem a expressão de idéias originais, da fantasia e do afeto. Trata-se de uma forma de ensino que prioriza a razão e aprisiona o corpo, evitando que este seja um canal de expressão (Silva, 1994).

Todavia, se a escola pretende formar indivíduos que sejam bem sucedidos em sua vida pessoal e profissional, é relevante que não negligencie a criatividade. Ao contrário, parece ser imprescindível incorporar a criatividade como um dos componentes fundamentais de seu currículo, pois diz respeito a algo que todos temos em diferentes medidas, podendo ser desenvolvida em vários níveis. É um processo dinâmico que requer interação com o meio. Uma habilidade que pode ser treinada e, por isso, seus componentes devem ser desenvolvidos e encorajados (Morgan \& Forster, 1999).

A escola precisa superar o modelo tradicional de ensino, que tem forte ênfase na memorização e reprodução do conhecimento. Deve passar a cultivar o pensamento crítico e criador no aluno, para minimizar problemas sócio-educacionais com os quais convive atualmente, como o fracasso escolar, a baixa motivação, a evasão e a repetência, a fim de caminhar para uma educação de melhor qualidade. Para tanto, faz-se necessário estabelecer um clima em sala de aula que seja propício à emergência e ao desenvolvimento de habilidades criativas que, segundo Martínez (2002), requer focalizar o trabalho em três direções: alunos, educadores e escola como organização. De forma similar, Renzulli (1992), autor da teoria para o desenvolvimento da criatividade produtiva em pessoas jovens, chama atenção para três componentes: o professor, considerado o elemento mais importante, o aluno e o currículo, apontando especialmente características do professor que facilitam o florescimento da criatividade em sala de aula, a saber: conhecimento da disciplina (domínio de conteúdo de sua área), uso de uma diversidade de técnicas instrucionais que facilitam e encorajam a criatividade e romance com a disciplina, ou seja, amor pelo ensino e pelo que ensina.
Estudiosos da criatividade têm sugerido várias maneiras de cultivá-la em sala de aula (Alencar, 1996; Alencar \& Fleith, 2003a; Cropley, 2005; Fleith, 2002, 2007a, 2007b; Martínez, 1997; Miranda, 2005; Nakano \& Wechsler, 2007; Wechsler, 2002a). Sinalizam também características relacionadas à personalidade criativa, relevantes de serem conhecidas e estimuladas pelos docentes: a) fluência de idéias, b) flexibilidade, c) originalidade, d) elaboração de ideias com detalhes, com o uso elevado de analogias e combinações incomuns, e) sensibilidade para problemas, f) autoconfiança, g) autonomia, h) persistência, i) fantasia e imaginação, j) preferência por situações de risco, 1) motivação intrínseca e curiosidade, $\mathrm{m}$ ) elevado senso de humor, $n$ ) espontaneidade.

Uma análise da literatura indica que muitos estudos foram realizados sobre criatividade no contexto educacional, sobretudo com amostras de professores e alunos do ensino fundamental (Ai-Girl, 2001; Aljughaiman \& MowrerReynolds, 2005; Carvalho \& Alencar, 2004; Castro, 2007; Dias, Enumo, \& Azevedo Junior, 2004; Fleith \& Alencar, 2006; Mariani \& Alencar, 2005; Werlang, 2005), educação superior (Alencar, 1995, 1997; Alencar \& Fleith, 2004a; Becker e cols., 2001; Castanho, 2000; Oliveira, 2007; Ribeiro \& Fleith, 2007; Santeiro, Santeiro, \& Andrade, 2004; Silva \& Alencar, 2003; Souza \& Alencar, 2006) e pós-graduação (Alencar, 2000, 2002). Entretanto, há escassez de estudos com dados obtidos junto a professores e alunos do ensino médio.

Entre as pesquisas com alunos do ensino fundamental, poder-se-ia apontar a realizada por Fleith (2000), que investigou a percepção de professores e alunos de $3^{\mathrm{a}}$ e $4^{\mathrm{a}}$ séries quanto a características que estimulam ou inibem o desenvolvimento de criatividade no ambiente de sala de aula. A autora constatou que tanto professores como estudantes apontaram as atitudes do professor como foco principal e favorecedor à expressão da criatividade. Atitudes docentes, como não imposição de muitas tarefas e regras aos alunos; concessão do direito de escolha aos estudantes; oferecimento de oportunidades para que eles tenham consciência da sua capacidade criativa; aceitação dos estudantes como são; e encorajamento da autoconfiança; fizeram parte do rol de atitudes favorecedoras à expressão e desenvolvimento da criatividade.

Ainda no que tange ao ensino fundamental, Castro (2007) investigou, entre outros aspectos, a percepção do clima em sala de aula para a criatividade em uma amostra de 967 alunos da $4^{\text {a }}$ série do ensino fundamental. Os resultados indicaram que maior suporte da professora à expressão de ideias e um clima mais estimulador do interesse pela aprendizagem foram apontados pelos alunos de professores com maior experiência docente.

Estudos foram também realizados com professores de disciplinas específicas do ensino fundamental, como Geografia e História. Mariani e Alencar (2005) investigaram, por exemplo, os componentes da organização do trabalho pedagógico e elementos de caráter pessoal/individual que agem como inibidores e facilitadores da expressão da criatividade do docente em uma amostra de professores de História. 
Vários aspectos foram identificados como estímulos à criatividade no trabalho docente; entre eles, liberdade e paixão pelo trabalho. Em contrapartida, problemas no relacionamento professor-aluno foi um dos limites apontados. Por outro lado, Carvalho e Alencar (2004) investigaram elementos favorecedores e inibidores da criatividade dos alunos, segundo professores de Geografia do ensino fundamental. As práticas pedagógicas consideradas pelos professores como as que melhor favorecem o desenvolvimento da criatividade dos alunos estavam mais relacionadas a procedimentos que facilitam a aprendizagem de conteúdos, do que à promoção da criatividade, como, por exemplo, esclarecer as dúvidas dos alunos e fazer conexões entre o que está sendo abordado em sala de aula com outros temas da atualidade. Ademais, as barreiras à promoção da criatividade em sala de aula mais indicadas estavam relacionadas aos alunos, como, por exemplo, elevado número de alunos em sala de aula e presença de alunos indisciplinados que perturbam o trabalho docente, o que indica dificuldade do professor em manter o interesse, a atenção, a participação e a promoção da aprendizagem de todos. Outros estudos a respeito de barreiras à criatividade pessoal, entre professores de distintos níveis de ensino, apontaram a falta de tempo e oportunidade como o fator mais mencionado pelos docentes pesquisados (Alencar \& Fleith, 2003b; Castro, 2007; Ribeiro \& Fleith, 2007).

$\mathrm{Na}$ educação superior, Alencar $(1995,1997)$ constatou que os estudantes universitários consideram que há pouco incentivo a distintos aspectos da criatividade por parte de seus professores. Quando avaliaram o seu próprio nível de criatividade, observou-se que estudantes do sexo masculino, que estavam na segunda metade do curso e que trabalhavam, consideraram-se como mais criativos do que os do sexo feminino, da primeira metade do curso e que somente estudavam. Além disso, os resultados indicaram que os universitários percebiam, de modo geral, os seus professores como pouco ou muito pouco criativos.

Em estudo mais recente, com uma amostra de professores e alunos da educação superior, Alencar e Fleith (2004a) constataram que os professores se avaliaram de forma muito mais positiva do que os seus alunos no que diz respeito às práticas pedagógicas utilizadas. Resultados similares a estes foram obtidos por Ribeiro e Fleith (2007) em um estudo com alunos e professores de cursos de licenciatura, por Silva e Alencar (2003) com professores e alunos do curso de Enfermagem e por Souza e Alencar (2006), em uma pesquisa com professores e estudantes do curso de Pedagogia.

No que diz respeito ao ensino médio, observa-se escassez de estudos empíricos focalizando as práticas utilizadas pelos docentes para promover a expressão e o desenvolvimento do potencial criativo dos alunos, com dados levantados seja junto a professores, seja junto a alunos. Considera-se, no entanto, que este nível de ensino exige mudanças estruturais, pois nasceu e cresceu em meio ao ensino fundamental e à educação superior, o que prejudicou a formação de sua identidade, bem como dificultou melhorias quanto a recursos, espaços e objetivos. Tal afirmação pode ser confirmada por Gomes (2000), quando compara o ensino médio a um patinho feio que precisa se tornar cisne e deixar de receber migalhas do bando. Nesse sentido, muito ainda necessita ser feito para conseguir transformar "o pato em cisne". Entre outras medidas, está o ensino que possibilite o desenvolvimento da criatividade.

Para alcançar essa meta, faz-se necessário repensar o conteúdo a ser ensinado, a formação dos professores e a qualidade da educação daqueles que ingressam no sistema educacional. Isto envolve vencer a crise que o sistema educacional brasileiro enfrenta no século XXI, pois é sabido que, embora tenha apresentado expansão no número de matrículas, apresentou também o empobrecimento da qualidade da educação. Dados do Instituto Nacional de Estudos e Pesquisas Educacionais Anísio Teixeira (INEP), por exemplo, evidenciam que a educação tem apresentado diferença de resultados entre a rede pública e a particular, e entre escolas de distintas regiões do país. A queda de desempenho mostrou-se um problema que afeta mais a rede pública e os Estados das regiões mais pobres, onde há professores menos qualificados, que recebem menores salários e com mais estudantes na zona rural e com recursos escolares mais restritos (Ministério da Educação, 2004).

É relevante ressaltar que, na Reunião Internacional de Especialistas, realizada em 2001, em Beijing, com o tema "Ensino Médio Geral no Século XXI: desafios, tendências e prioridades", obteve-se consenso no que diz respeito à necessidade de uma redefinição nos objetivos e funções do ensino médio de forma a atender a "vontade clara e urgente de tratar este nível de ensino como uma área autônoma de pleno direito, e não mais como uma simples extensão do sistema de educação básica ou um filtro para o acesso à educação superior" (Organização das Nações Unidas para Educação, Ciência e Cultura [UNESCO], 2003, p. 67).

Também nos Parâmetros Curriculares Nacionais houve notória redefinição dos princípios gerais para orientação e reformulação do currículo, de forma a conferir nova identidade ao ensino médio, tendo como prioridade a aquisição de conhecimentos básicos, a preparação científica e a capacidade de utilizar as diferentes tecnologias relativas às áreas de atuação. Isto significa uma formação geral, em oposição à formação específica. Os objetivos do ensino médio passaram a ser, então, o desenvolvimento da capacidade de pesquisar, buscar informações, analisá-las e selecioná-las; a capacidade de aprender, criar, formular, ao invés do simples exercício de memorização (Ministério da Educação, 1999). São estes os princípios mais gerais que orientam a reformulação curricular do ensino médio e que se expressam também na nova Lei de Diretrizes e Bases da Educação - Lei No. 9.394/96 (1996).

Nota-se que, apesar do reconhecimento crescente da importância de se promover a criatividade no ensino médio, há carência de estudos empíricos a respeito da extensão em que a mesma vem sendo contemplada nesse nível de ensino. Este fator, aliado ao interesse pelo tema, levou-nos ao 
desenvolvimento deste estudo, de natureza quali-quantitava, que teve como objetivos investigar a percepção de estudantes do ensino médio quanto ao nível de sua criatividade, do de seus professores e colegas, bem como identificar a extensão em que práticas docentes que promovem a expressão e o desenvolvimento da criatividade têm sido implementadas por seus professores, segundo esses estudantes.

\section{Método}

\section{Participantes}

Participaram do estudo 217 alunos do ensino médio de uma escola da rede particular de uma cidade do noroeste mineiro, sendo $112(51,6 \%)$ dos respondentes do sexo masculino e $105(48,4 \%)$ do sexo feminino, 82 alunos cursavam a $1^{\mathrm{a}}$ série, 64 a $2^{\mathrm{a}}$ série e 71 a $3^{\mathrm{a}}$ série. A média de idade dos participantes foi de 15,75 anos, variando de 13 a 18 anos.

\section{Instrumentos}

Para identificar a percepção dos alunos quanto ao nível de sua criatividade, do de seus professores e colegas, foi utilizada a Escala de Avaliação do Nível de Criatividade, que inclui as seguintes questões: Como você se avalia em uma escala de criatividade? Como você avalia o nível de criatividade de seus professores? Como você avalia o nível de criatividade dos seus colegas? Estes itens foram respondidos em uma das seguintes opções: nada criativo(a); muito pouco criativo(a); pouco criativo(a); criativo(a); muito criativo(a); muitíssimo criativo(a) e extremamente criativo(a).

Para avaliar a percepção dos alunos a respeito da extensão em que seus professores apresentam comportamentos e implementam práticas docentes que favorecem o desenvolvimento e expressão da criatividade discente, utilizou-se uma questão aberta "Na sua opinião, os professores do Ensino Médio têm contemplado o desenvolvimento e a expressão do potencial criativo dos alunos? Justifique a resposta" e o Inventário de Avaliação de Práticas Docentes, construído e validado por Alencar (1995, 1997).

O referido inventário é composto de 19 itens, que são respondidos em uma escala de cinco pontos, variando de "discordo plenamente" a "concordo plenamente". O estudo de validação do mesmo indicou um único fator, tendo sido obtido um coeficiente alfa de consistência interna de 0,90 .

Cabe informar que o Inventário de Avaliação de Práticas Docentes foi atualizado por Alencar e Fleith (2004b) e validado em uma amostra de estudantes da educação superior. Nesta nova versão, avalia-se a percepção do estudante quanto às práticas docentes de apenas um de seus professores. O mesmo não foi utilizado no presente estudo, dado o interesse em identificar a percepção no que diz respeito à prática docente dos professores do ensino médio, de modo geral. Pesquisar por disciplina implicaria necessidade de o aluno responder o inventário cerca de dez vezes, em função do número de disciplinas que há neste nível de ensino.

\section{Considerações éticas}

Foram tomados todos os cuidados éticos necessários, garantindo-se o sigilo e a opção dos alunos em participar ou não da pesquisa.

\section{Procedimentos}

Coleta de dados

O questionário foi aplicado em horários de aula pela primeira autora. Os alunos foram solicitados a colaborar e informados que não se tratava de uma pesquisa realizada pela escola, mas um trabalho para o curso de mestrado da primeira autora. A participação foi, pois, voluntária, tendo sido ainda solicitado aos alunos o cuidado de responder com seriedade, para não distorcer os dados para análise.

\section{Análise dos dados}

Utilizou-se o pacote estatístico SPSS para a análise dos dados obtidos por meio da Escala de Avaliação do Nível de Criatividade e pelo Inventário de Avaliação de Práticas Docentes. Foram calculados a média e o desvio padrão de cada um dos itens e ainda a média e desvio padrão geral no Inventário de Avaliação de Práticas Docentes. Foi utilizada análise de variância para identificar possíveis diferenças entre médias nas três avaliações quanto ao nível de criatividade. Para interpretação das respostas à questão aberta, foi utilizada análise de conteúdo, empregando-se o método lógico-semântico, descrito por Franco (2005), de forma a categorizar a posteriori as respostas dos participantes da pesquisa.

\section{Resultados}

\section{Avaliação do nível de criatividade pessoal e do nível de criatividade de seus professores e colegas por parte dos alunos}

$\mathrm{Na}$ Tabela 1, são apresentados a média e o desvio padrão nas avaliações do nível de criatividade pessoal e dos professores e colegas. A análise de variância efetuada indicou diferenças significativas entre as três avaliações $(\mathrm{F}[2,647]=28,525 ; \mathrm{p}=0,0001)$. Utilizou-se o teste Scheffé para verificar o nível de significância das diferenças entre médias nas referidas avaliações. Por esta análise, observouse que a média na autoavaliação do nível de criatividade (M $=4,35)$ foi significativamente superior à referente à avaliação do nível de criatividade dos professores $(\mathrm{M}=3,51$; $\mathrm{p}$ $=0,0001)$ e ainda significativamente superior à referente à avaliação do nível de criatividade dos colegas $(\mathrm{M}=3,90$; $\mathrm{p}=0,0001)$. Foi também significativa a diferença entre a média obtida na avaliação dos colegas e dos professores no que diz respeito ao nível de criatividade, a favor dos primeiros $(\mathrm{p}=0,0001)$. 
Tabela 1

Média e desvio padrão na avaliação, por parte dos alunos, do seu nivel de criatividade, de seus professores e colegas

\begin{tabular}{lcc}
\hline Avaliação do Nível de Criatividade & Média & Desvio Padrão \\
\hline Avaliação de si mesmo(a) & 4,35 & 1,12 \\
Avaliação de seus professores & 3,51 & 1,16 \\
Avaliação de seus colegas & 3,90 & 1,20 \\
\hline
\end{tabular}

Expressão e desenvolvimento da criatividade no ensino médio, segundo a percepção dos alunos

A questão aberta foi respondida por 207 alunos $(95,39 \%$ dos participantes) e, destes, 197 (90,78\% do total) justificaram a resposta. Constatou-se que 42 alunos (19,35\%) responderam afirmativamente, 71 alunos $(32,72 \%)$ concordaram parcialmente, ao passo que $94(43,32 \%)$ responderam negativamente.

Um exame das justificativas dos alunos que responderam afirmativamente indicou que as mesmas se classificaram nas seguintes categorias: (1) Desenvolvimento do potencial criativo associado à realização, pelo professor, de atividades lúdicas, ao uso de recursos audiovisuais e à discussão de temas da atualidade: Eles procuram formas diferentes de dar as aulas, levando ao auditório, mostrando slides; Tratam de assuntos atuais que acontecem no país e no mundo, causando boas discussões; Trazem curiosidades para a sala de aula. (2) Vontade de aprender associada à realização de aulas e atividades criativas: Dão trabalhos criativos que fazem com que o aluno queira fazer, queira saber sobre o assunto. (3) Receptividade e estímulo à expressão de novas idéias: Aceitam as ideias e ajudam a elaborar ideias novas.

Alunos que concordaram parcialmente com o fato de que a criatividade é contemplada no ensino médio ressaltaram que apenas alguns professores saem da rotina, tornam as aulas mais interessantes e, por consequência, valorizam e oferecem oportunidades para o desenvolvimento da criatividade. As seguintes categorias foram identificadas na análise das respostas desses alunos: (1) Associação entre inovação nas aulas e interesse dos alunos: Alguns inovam e trazem sempre algo novo e as aulas ficam mais interessantes. (2) Discrepância entre professores quanto ao domínio do conteúdo: Alguns sim, outros nem sequer dominam com facilidade o conteúdo. (3) Discrepância entre aulas monótonas e aulas dinâmicas: Em algumas disciplinas as aulas são monótonas, as quais deixam a desejar. Porém, há disciplinas que desenvolvem a criatividade de seus alunos, tornando as aulas bem dinâmicas e instigantes.

As justificativas dos alunos que responderam negativamente se enquadraram nas seguintes categorias: (1) Pouca variedade nas metodologias de ensino: Os professores não trazem nada de diferente para as aulas. É sempre a mesma coisa. (2) Ênfase exagerada no conteúdo e em sua reprodução: Com exceção de alguns professores, eles só querem saber de cumprir com a apostila. Não querem saber se aprendemos e se concordamos com a maneira que aprendemos. (3) Disciplinas ministradas de forma tradicional: Os professores somente dão as aulas do tipo convencional. Nunca dão aulas dinâmicas, visando despertar a criatividade dos alunos. (4) Falta de tempo para a expressão e desenvolvimento de ideias novas: Devido ao pouco tempo de aula, os alunos não têm liberdade de expressar seus pensamentos e desenvolver sua criatividade.

Na Tabela 2, são apresentados os resultados obtidos no Inventário de Avaliação de Práticas Docentes. Como pode ser observado na tabela, a média nos itens variou de 2,53 a 3,39 , enquanto a média geral foi de 3,03 e o desvio padrão 1,04. As maiores médias foram nos itens: "Estimulam os alunos a analisar diferentes aspectos de um problema" $(\mathrm{M}=$ $3,38)$ e "Levam o aluno a perceber e conhecer pontos de vista divergentes sobre o mesmo problema ou tema de estudo" $(\mathrm{M}=3,39)$. As menores médias foram nos itens "Promovem a autoconfiança dos seus alunos" ( $M=2,60)$ e "Procuram diversificar as metodologias de ensino utilizadas em suas disciplinas" $(\mathrm{M}=2,53)$.

Tabela 2

Frequência numérica, percentual, média e desvio padrão nos itens do Questionário de Avaliação de Procedimentos Docentes

\begin{tabular}{|c|c|c|c|c|c|c|c|}
\hline $\begin{array}{l}\text { Em sala de aula os meus professores, } \\
\text { de modo geral: }\end{array}$ & $\begin{array}{c}\text { Discordo } \\
\text { plenamente }\end{array}$ & Discordo & $\begin{array}{l}\text { Estou } \\
\text { em } \\
\text { dúvida }\end{array}$ & Concordo & $\begin{array}{c}\text { Concordo } \\
\text { plenamente }\end{array}$ & Média & $\begin{array}{l}\text { Desvio } \\
\text { Padrão }\end{array}$ \\
\hline $\begin{array}{l}\text { 1. Cultivam nos alunos o gosto pela descoberta e } \\
\text { pela busca de novos conhecimentos. }\end{array}$ & $\begin{array}{c}12 \\
(5,5 \%)\end{array}$ & $\begin{array}{c}64 \\
(29,5 \%)\end{array}$ & $\begin{array}{c}45 \\
(20,7 \%)\end{array}$ & $\begin{array}{c}83 \\
(38,2 \%)\end{array}$ & $\begin{array}{c}9 \\
(4,1 \%)\end{array}$ & 3,06 & 1,042 \\
\hline $\begin{array}{l}\text { 2. Fazem perguntas desafiadoras que motivam os } \\
\text { alunos a pensar e a raciocinar. }\end{array}$ & $\begin{array}{c}15 \\
(6,9 \%)\end{array}$ & $\begin{array}{c}50 \\
(23 \%)\end{array}$ & $\begin{array}{c}37 \\
(17,1 \%)\end{array}$ & $\begin{array}{c}103 \\
(47,5 \%)\end{array}$ & $\begin{array}{c}11 \\
(5,1 \%)\end{array}$ & 3,21 & 1,073 \\
\hline $\begin{array}{l}\text { 3. Estimulam os alunos a analisar diferentes } \\
\text { aspectos de um problema. }\end{array}$ & $\begin{array}{c}6 \\
(2,8 \%)\end{array}$ & $\begin{array}{c}42 \\
(19,4 \%)\end{array}$ & $\begin{array}{c}44 \\
(20,3 \%)\end{array}$ & $\begin{array}{c}112 \\
(51,6 \%)\end{array}$ & $\begin{array}{c}12 \\
(5,5 \%)\end{array}$ & 3,38 & 0,952 \\
\hline 4. Estimulam a iniciativa dos alunos. & $\begin{array}{c}14 \\
(6,5 \%)\end{array}$ & $\begin{array}{c}66 \\
(30,4 \%)\end{array}$ & $\begin{array}{c}40 \\
(18,4 \%)\end{array}$ & $\begin{array}{c}90 \\
(41,5 \%)\end{array}$ & $\begin{array}{c}6 \\
(2,8 \%)\end{array}$ & 3,04 & 1,047 \\
\hline $\begin{array}{l}\text { 5. Estimulam o aluno a pensar ideias novas } \\
\text { relacionadas ao conteúdo da matéria. }\end{array}$ & $\begin{array}{c}15 \\
(6,9 \%)\end{array}$ & $\begin{array}{c}58 \\
(26,7 \%)\end{array}$ & $\begin{array}{c}45 \\
(20,7 \%)\end{array}$ & $\begin{array}{c}84 \\
(38,7 \%)\end{array}$ & $\begin{array}{c}14 \\
(6,5 \%)\end{array}$ & 3,11 & 1,090 \\
\hline 6. Promovem a autoconfiança dos seus alunos. & $\begin{array}{c}34 \\
(15,7 \%)\end{array}$ & $\begin{array}{c}69 \\
(31,8 \%)\end{array}$ & $\begin{array}{c}68 \\
(31,3 \%)\end{array}$ & $\begin{array}{c}39 \\
(18 \%)\end{array}$ & $\begin{array}{c}6 \\
(2,8 \%)\end{array}$ & 2,60 & 1,043 \\
\hline
\end{tabular}


Tabela 2

(continuação)

\begin{tabular}{|c|c|c|c|c|c|c|c|}
\hline $\begin{array}{l}\text { Em sala de aula os meus professores, } \\
\text { de modo geral: }\end{array}$ & $\begin{array}{l}\text { Discordo } \\
\text { plenamente }\end{array}$ & Discordo & $\begin{array}{l}\text { Estou } \\
\text { em } \\
\text { dúvida }\end{array}$ & Concordo & $\begin{array}{l}\text { Concordo } \\
\text { plenamente }\end{array}$ & Média & $\begin{array}{l}\text { Desvio } \\
\text { Padrão }\end{array}$ \\
\hline $\begin{array}{l}\text { 7. Estimulam a curiosidade dos alunos através das } \\
\text { tarefas propostas em suas disciplinas. }\end{array}$ & $\begin{array}{c}23 \\
(10,6 \%)\end{array}$ & $\begin{array}{c}83 \\
(38,2 \%)\end{array}$ & $\begin{array}{c}41 \\
(18,9 \%)\end{array}$ & $\begin{array}{c}60 \\
(27,6 \%)\end{array}$ & $\begin{array}{c}9 \\
(4,1 \%)\end{array}$ & 2,76 & 1,097 \\
\hline 8. Incentivam a independência dos seus alunos. & $\begin{array}{c}15 \\
(6,9 \%)\end{array}$ & $\begin{array}{c}45 \\
(20,7 \%)\end{array}$ & $\begin{array}{c}52 \\
(24,0 \%)\end{array}$ & $\begin{array}{c}93 \\
(42,9 \%)\end{array}$ & $\begin{array}{c}10 \\
(4,6 \%)\end{array}$ & 3,18 & 1,040 \\
\hline $\begin{array}{l}\text { 9. Desenvolvem nos alunos habilidades de análise } \\
\text { crítica. }\end{array}$ & $\begin{array}{c}17 \\
(7,8 \%)\end{array}$ & $\begin{array}{c}50 \\
(23 \%)\end{array}$ & $\begin{array}{c}36 \\
(16,6 \%)\end{array}$ & $\begin{array}{c}99 \\
(45,6 \%)\end{array}$ & $\begin{array}{c}12 \\
(5,5 \%)\end{array}$ & 3,18 & 1,100 \\
\hline $\begin{array}{l}\text { 10. Levam o aluno a perceber e conhecer os pontos } \\
\text { de vista divergentes sobre o mesmo problema ou } \\
\text { tema de estudo. }\end{array}$ & $\begin{array}{c}12 \\
(5,5 \%)\end{array}$ & $\begin{array}{c}35 \\
(16,1 \%)\end{array}$ & $\begin{array}{c}42 \\
(19,4 \%)\end{array}$ & $\begin{array}{c}112 \\
(51,6 \%)\end{array}$ & $\begin{array}{c}16 \\
(7,4 \%)\end{array}$ & 3,39 & 1,022 \\
\hline 11. Valorizam as ideias originais de seus alunos. & $\begin{array}{c}23 \\
(10,6 \%)\end{array}$ & $\begin{array}{c}58 \\
(26,7 \%)\end{array}$ & $\begin{array}{c}45 \\
(20,7 \%)\end{array}$ & $\begin{array}{c}73 \\
(33,6 \%)\end{array}$ & $\begin{array}{c}16 \\
(7,4 \%)\end{array}$ & 3,00 & 1,158 \\
\hline $\begin{array}{l}\text { 12. Incentivam os alunos a proporem questões } \\
\text { relativas aos temas estudados. }\end{array}$ & $\begin{array}{c}21 \\
(9,7 \%)\end{array}$ & $\begin{array}{c}73 \\
(33,6 \%)\end{array}$ & $\begin{array}{c}42 \\
(19,4 \%)\end{array}$ & $\begin{array}{c}69 \\
(31,8 \%)\end{array}$ & $\begin{array}{c}12 \\
(5,5 \%)\end{array}$ & 2,90 & 1,122 \\
\hline $\begin{array}{l}\text { 13. Preocupam-se apenas com o conteúdo } \\
\text { informativo de suas disciplinas. }\end{array}$ & $\begin{array}{c}13 \\
(6,0 \%)\end{array}$ & $\begin{array}{c}61 \\
(28,1 \%)\end{array}$ & $\begin{array}{c}22 \\
(10,1 \%)\end{array}$ & $\begin{array}{c}79 \\
(36,4 \%)\end{array}$ & $\begin{array}{c}40 \\
(18,4 \%)\end{array}$ & 3,33 & 1,238 \\
\hline $\begin{array}{l}\text { 14. Criam um ambiente de respeito e aceitação } \\
\text { pelas idéias dos alunos. }\end{array}$ & $\begin{array}{c}23 \\
(10,6 \%)\end{array}$ & $\begin{array}{c}45 \\
(20,7 \%)\end{array}$ & $\begin{array}{c}44 \\
(20,3 \%)\end{array}$ & $\begin{array}{c}92 \\
(42,4 \%)\end{array}$ & $\begin{array}{c}12 \\
(5,5 \%)\end{array}$ & 3,12 & 1,129 \\
\hline $\begin{array}{l}\text { 15. Dão tempo aos alunos para pensar e } \\
\text { desenvolver ideias novas. }\end{array}$ & $\begin{array}{c}43 \\
(19,8 \%)\end{array}$ & $\begin{array}{c}70 \\
(32,3 \%)\end{array}$ & $\begin{array}{c}31 \\
(14,3 \%)\end{array}$ & $\begin{array}{c}57 \\
(26,3 \%)\end{array}$ & $\begin{array}{c}16 \\
(7,4 \%)\end{array}$ & 2,69 & 1,259 \\
\hline $\begin{array}{l}\text { 16. Dão chances aos alunos para discordar de seus } \\
\text { pontos de vista. }\end{array}$ & $\begin{array}{c}24 \\
(11,1 \%)\end{array}$ & $\begin{array}{c}65 \\
(30,0 \%)\end{array}$ & $\begin{array}{c}43 \\
(19,8 \%)\end{array}$ & $\begin{array}{c}72 \\
(33,2 \%)\end{array}$ & $\begin{array}{c}13 \\
(6,0 \%)\end{array}$ & 2,93 & 1,147 \\
\hline $\begin{array}{l}\text { 17. Utilizam formas de avaliações que exigem do } \\
\text { aluno apenas a reprodução do conteúdo dado em } \\
\text { classe ou contido nos livros textos. }\end{array}$ & $\begin{array}{c}28 \\
(12,9 \%)\end{array}$ & $\begin{array}{c}54 \\
(24,9 \%)\end{array}$ & $\begin{array}{c}26 \\
(12,0 \%)\end{array}$ & $\begin{array}{c}86 \\
(39,6 \%)\end{array}$ & $\begin{array}{c}21 \\
(9,7 \%)\end{array}$ & 3,08 & 1,250 \\
\hline $\begin{array}{l}\text { 18. Apresentam vários aspectos de uma questão que } \\
\text { está sendo estudada. }\end{array}$ & $\begin{array}{c}19 \\
(8,8 \%)\end{array}$ & $\begin{array}{c}62 \\
(28,6 \%)\end{array}$ & $\begin{array}{c}40 \\
(18,4 \%)\end{array}$ & $\begin{array}{c}84 \\
(38,7 \%)\end{array}$ & $\begin{array}{c}10 \\
(4,6 \%)\end{array}$ & 3,02 & 1,106 \\
\hline $\begin{array}{l}\text { 19. Procuram diversificar as metodologias de } \\
\text { ensino utilizadas em suas disciplinas. }\end{array}$ & $\begin{array}{c}51 \\
(23,5 \%) \\
\end{array}$ & $\begin{array}{c}72 \\
(33,2 \%)\end{array}$ & $\begin{array}{c}34 \\
(15,7 \%)\end{array}$ & $\begin{array}{c}46 \\
(21,2 \%)\end{array}$ & $\begin{array}{c}13 \\
(6,0 \%)\end{array}$ & 2,53 & 1,231 \\
\hline
\end{tabular}

Nota: Os valores obtidos nos itens 13 e 17 foram invertidos para cálculo da média geral.

Média Geral $=3,03$; Desvio Padrão Geral $=1,04$

Observa-se que a média geral, 3,03, corresponde à opção "Estou em dúvida". Ademais, a maior parte das respostas aos itens, divide-se entre as opções "Concordo" ou "Discordo".

\section{Discussão}

Na avaliação do nível de criatividade dos alunos, professores e colegas, constatou-se que os alunos do ensino médio se perceberam predominantemente como criativos ou muito criativos. Os docentes foram avaliados pelos estudantes como significativamente menos criativos do que eles próprios e do que os seus colegas. Resultados parcialmente semelhantes foram obtidos por Silva e Alencar (2003) em uma amostra de alunos do curso de Enfermagem de uma universidade pública e por Alencar (1997, 2002), em estudos com estudantes universitários e pós-graduandos de uma universidade pública. Diferentemente do que foi observado no presente estudo, tanto Alencar (1997) como Silva e Alencar (2003) não observaram diferenças entre a autoavaliação dos alunos e a avaliação destes, quanto ao nível de criatividade dos seus colegas.

No que diz respeito à questão aberta, mais da metade dos alunos concordou total ou parcialmente que, de modo geral, os professores do ensino médio têm contemplado, em suas aulas, o desenvolvimento e a expressão do potencial criativo de seus alunos. Estes resultados estão em discordância com os encontrados por Silva e Alencar (2003) em um estudo que envolveu alunos e professores do curso de Enfermagem, de uma universidade pública e também com os obtidos por Oliveira (2007), em pesquisa envolvendo professores do curso de Letras de distintas instituições de educação superior. Estão, porém, em congruência com os encontrados por Souza e Alencar (2006), em estudo realizado com professores e estudantes do curso de Pedagogia.

A presença da criatividade nas salas de aula do ensino médio, sob a percepção dos alunos, reforça a ideia de Martínez (1997) quando esta afirma ser a criatividade uma habilidade que se manifesta em diferentes níveis e campos da atividade humana, não se restringindo a apenas algumas. Reforça ainda a importância do ambiente educacional para a criatividade, conforme destacaram Alencar (1995, 2001), Alencar e Fleith (2003a), Bono (1994), Castanho (2000), Fleith (2000), Morgan e Foster (1999) e Wechsler (2002a, 2002b).

A análise das justificativas das respostas dos alunos à questão aberta revelou que vários deles, ao concordar com 
a existência da expressão e desenvolvimento da criatividade propiciados por seus professores em sala de aula, deram crédito à realização de atividades lúdicas, ao uso de recursos audiovisuais, à discussão de temas da atualidade, à aceitação de suas ideias e ao incentivo para elaborar novas ideias. Resultados em harmonia com a opinião dos professores de Geografia do ensino fundamental em estudo realizado por Carvalho e Alencar (2004), no qual práticas pedagógicas consideradas como as que mais favoreciam o desenvolvimento da criatividade dos alunos estavam mais relacionadas a procedimentos que facilitavam a aprendizagem de conteúdos.

Uma análise das respostas apresentadas pelos alunos indicou que vários deles associaram criatividade à realização de algo novo ou praticado de forma diferenciada, com valor para este grupo de pessoas, conforme apontaram Alencar (1996, 2001), Bono (1994), Cheung e cols. (2003), Feldman e cols. (1994) e ainda com o sinalizado por Martínez (2006), a qual relacionou a criatividade no trabalho pedagógico às novidades nas formas de se ensinar e educar, com resultados valiosos para a aprendizagem e desenvolvimento dos alunos.

Entre os alunos que discordaram da ideia de que a criatividade seja desenvolvida em sala de aula, vários deles revelaram que há pouca variedade nas metodologias de ensino, deixando as aulas monótonas e cansativas, prejudicando o interesse geral pela escola e pela aprendizagem. Este julgamento vai ao encontro dos resultados encontrados por Silva e Alencar (2003), Ribeiro e Fleith (2007), Souza e Alencar (2006) que também identificaram diferenças entre a percepção de professores e alunos. Os professores consideraram que estimulam o desenvolvimento e a expressão criativa dos alunos, enquanto os discentes não concordaram com seus mestres. Ressalta-se que, em estudo realizado por Oliveira (2007) com professores do curso de Letras, foi identificada ausência, na formação destes professores, de informações sobre criatividade e oportunidades de atualização. Os resultados do estudo revelaram ainda que, para alguns participantes, a ênfase exagerada no conteúdo e em sua reprodução, bem como a forma tradicional de ministrar as disciplinas escolares, são fatores que atrapalham a expressão e o desenvolvimento da criatividade, além da falta de tempo para expressão e incremento de ideias novas. Em consonância com estes resultados, o fator Falta de Tempo/Oportunidade também foi encontrado como uma barreira à criatividade em outros estudos, como os realizados por Alencar e Fleith (2003b), por Castro (2007) e por Ribeiro e Fleith (2007).

Os alunos que concordaram parcialmente com o desenvolvimento da criatividade nas salas de aula do ensino médio revelaram que alguns professores inovam e que tais inovações propiciam o interesse dos alunos pela disciplina. Resultados em consenso com estes foram encontrados por Fleith (2000), a qual constatou que tanto professores como alunos mostraram acreditar na importância das atitudes do professor para possibilitar a expressão da criatividade.

Vários alunos do ensino médio também afirmaram que, enquanto alguns professores desenvolvem bem suas aulas e a criatividade, outros sequer dominam o conteúdo da disciplina. Além disso, para estes alunos, há uma discrepância entre os professores, pois, enquanto alguns conduzem aulas dinâmicas, outros não mudam a rotina, deixando as aulas muito monótonas. Esta constatação está em consonância com resultados de um estudo realizado por Alencar (2000), em que os alunos envolvidos na pesquisa apontaram o pouco domínio da disciplina lecionada, o conteúdo da disciplina muito restrito e com indicação de poucas referências a serem consultadas, como algumas das características identificadoras do professor inibidor da criatividade. Outrossim, os resultados reforçam a importância do papel do professor no desenvolvimento do talento criador, além da predominância em sala de aula de um clima favorável à expressão da criatividade revelados nos resultados de estudo realizado por Fleith (2000).

Ao avaliar os procedimentos docentes, os alunos das três séries apresentaram opiniões divergentes, com grande parte das respostas se dividindo entre Concordo e Discordo. Ademais, uma análise das respostas revelou que as práticas docentes favorecedoras da criatividade mais utilizadas pelos seus professores são o estímulo à análise de diferentes aspectos de um problema, além da percepção e conhecimento dos pontos de vista divergentes sobre o mesmo problema ou tema em estudo. Estes itens fazem parte do rol de estratégias destacadas por estudiosos da área para o cultivo da criatividade em sala de aula (Alencar, 1996; Alencar \& Fleith, 2003a; Cropley, 2005; Fleith, 2002; Miranda, 2005; Martínez, 1997; Wechsler, 2002a). Em contrapartida, os alunos apontaram a promoção da autoconfiança como uma das práticas menos utilizadas pelos seus professores. Ressalta-se que vários autores, como Alencar e Fleith (2003a) e Fleith (2002), têm destacado que estimular características como persistência, autoconfiança, independência e disposição para aprender a partir dos próprios erros são práticas docentes a serem adotadas para se estabelecer um clima em sala de aula propício à emergência e ao desenvolvimento de habilidades criativas.

A diversidade nas metodologias de ensino utilizadas nas disciplinas também foi apontada pelos alunos como uma das práticas menos adotadas pelos seus professores. Em consenso com este resultado estão os encontrados por Alencar e Fleith (2004a), em estudo que envolveu professores e graduandos, em que os alunos avaliaram seus professores como menos favoráveis no fator Avaliação e Metodologia de Ensino.

Os resultados do presente estudo sugerem que nas disciplinas do ensino médio são oferecidas possibilidades limitadas ao desenvolvimento e expressão da capacidade de criar de seus estudantes, contemplando esse nível de ensino a expressão e o desenvolvimento da criatividade em níveis não muito expressivos. Há alguns professores empenhados em construir um ambiente de aprendizagem de excelência e promotor da criatividade, enquanto outros precisam rever várias de suas práticas no sentido de fomentar a expressão criativa. 
Percebe-se que o sistema educacional do país ainda tem uma estrutura curricular que dificulta o desenvolvimento e a expressão da criatividade de forma plena. Faz-se necessário repensar seus objetivos, métodos, formação docente, avaliação e clima em sala de aula, com vistas ao oferecimento de um contexto que tenha, segundo Quintián (2006), uma variedade de oportunidades e atividades capazes de fomentar a criatividade do indivíduo envolvido no sistema. Ademais, em função da importância da criatividade no atual cenário, que está por exigir indivíduos com competência para lidar criativamente com problemas e desafios, recomenda-se que o professor deste nível de ensino esteja também atento à criatividade como um processo a ser cultivado e desenvolvido em sala de aula.

A presente pesquisa, em que pese a sua contribuição para ampliar o conhecimento a respeito da criatividade no contexto educacional, requer aprofundamentos. Desta forma, sugerese que novos estudos sobre criatividade com foco neste nível de ensino sejam realizados e que estes envolvam professores e alunos, direção e também pais de alunos. Como sugestões para futuras pesquisas, poder-se-iam apontar: a) investigar as concepções de criatividade pelos alunos, pois isto contribuirá com a compreensão das diferenças de opinião na concordância ou discordância de que a criatividade venha sendo contemplada pelos professores do ensino médio, b) identificar as barreiras encontradas pelos professores do ensino médio para o desenvolvimento e expressão da criatividade discente, c) comparar a percepção de professores e alunos no que diz respeito à extensão em que a criatividade é contemplada no ensino médio, d) examinar possíveis diferenças entre instituições de ensino pública e particular no que diz respeito ao estímulo à criatividade em sala de aula, e) investigar junto a gestores e coordenadores pedagógicos os elementos que têm inibido ou facilitado a implementação de práticas pedagógicas voltadas para o desenvolvimento da criatividade no ensino médio, f) utilizar uma amostra maior, com participantes de diferentes regiões e culturas. Dada a relevância do tema focalizado na pesquisa e escassez de estudos empíricos, considera-se que muito mais necessita ser investigado a respeito da criatividade no ensino médio. O presente estudo constituiu apenas um passo nesta direção.

\section{Referências}

Ai-Girl, T. (2001). Singaporean teachers' perception of activities useful for fostering creativity. Journal of Creative Behavior, 35, 131-148.

Alencar, E. M. L. S. (1995). Developing creative abilities at the university level. European Journal for High Ability, 6, 82-90.

Alencar, E. M. L. S. (1996). A gerência da criatividade. São Paulo: Makron Books.

Alencar, E. M. L. S. (1997). O estímulo à criatividade no contexto universitário. Psicologia Escolar e Educacional, 1(2-3), 29-37.
Alencar, E. M. L. S. (2000). O perfil do professor facilitador e do professor inibidor da criatividade segundo estudantes de pós-graduação. Boletim da Academia Paulista de Psicologia, 19, 84-94.

Alencar, E. M. L. S. (2001). Criatividade e educação de superdotados. Petrópolis, RJ: Vozes.

Alencar, E. M. L. S. (2002). O estímulo à criatividade em programas de pós-graduação segundo seus estudantes. Psicologia: Reflexão e Crítica, 15, 63-70.

Alencar, E. M. L. S., \& Fleith, D. S. (2003a). Criatividade: Múltiplas perspectivas (3a ed.). Brasília, DF: Editora Universidade de Brasília.

Alencar, E. M. L. S., \& Fleith, D. S. (2003b). Barreiras à criatividade pessoal entre professores de distintos níveis de ensino. Psicologia: Reflexão e Crítica, 16, 63-69.

Alencar, E. M. L. S., \& Fleith, D. S. (2004a). Creativity in university courses: Perceptions of professors and students. Gifted and Talented International, 19, 24-28.

Alencar, E. M. L. S., \& Fleith, D. S. (2004b). Inventário de práticas docentes que favorecem a criatividade no ensino superior. Psicologia: Reflexão e Crítica, 17, 105-110.

Aljughaiman, A., \& Mowrer-Reynolds, E. (2005). Teachers' conceptions of creativity and creative students. Journal of Creative Behavior, 39, 17-34.

Becker, M. A. D’A., Roazzi, A., Madeira, M. J. P., Arend, I., Schneider, D., Wainberg, L., \& Souza, B. C. (2001). Estudo exploratório da conceitualização de criatividade em estudantes universitários. Psicologia: Reflexão e Crítica, 14, 571-579.

Bono, E. (1994). Criatividade levada a sério: Como gerar ideias produtivas através do pensamento lateral. São Paulo: Pioneira.

Carvalho, O., \& Alencar, E. M. L. S. (2004). Elementos favorecedores e inibidores da criatividade na prática docente, segundo professores de geografia. Psico, 35, 213-221.

Castanho, M. E. L. M. (2000). A criatividade na sala de aula universitária. In I. P. A. Veiga \& M. E. L. M. Castanho (Orgs.), Pedagogia universitária: A aula em foco (pp. 75-89). Campinas, SP: Papirus.

Castro, J. S. R. (2007). Criatividade escolar: Relação entre tempo de experiência docente e tipo de escola. Dissertação de mestrado não publicada, Universidade de Brasília, Brasília, DF.

Cheung, C., Rudowicz, E., Yue, X., \& Kwan, A. (2003). Creativity of university students: What is the impact of field and year of study? Journal of Creative Behavior, $37,42-63$.

Cropley, A. J. (2005). Creativity in education and learning. London: Routledge.

Dias, T. L., Enumo, S. R. F., \& Azevedo, R. R. Jr. (2004). Influências de um programa de criatividade no desempenho cognitivo e acadêmico de alunos com dificuldade de aprendizagem. Psicologia em Estudo, 9, 429-437. 
Feldman, D. H., Csiksentmihalyi, M., \& Gardner, H. (1994). Changing the world: A framework for the study of creativity. Westport: Praeger.

Fleith, D. S. (2000). Creativity in the classroom: Teacher and student perceptions of creativity in the classroom environment. Roeper Review, 22, 148-152.

Fleith, D. S. (2002). Ambientes educacionais que promovem a criatividade e a excelência. Sobredotação, 3(2), 27-39.

Fleith, D. S. (2007a). A promoção da criatividade no contexto escolar. In A. M. R. Virgolim (Org.), Talento criativo: Expressão em múltiplos contextos (pp. 143-157). Brasília, DF: Editora Universidade de Brasília.

Fleith, D. S. (2007b). Como desenvolver a criatividade no contexto educacional. In Serviço Social da Indústria (SESI). Departamento Nacional (DN). Criatividade (Série Rede SESI de Educação, Vol. 12, pp. 9-29). Brasília, DF: SESI.

Fleith, D. S., \& Alencar, E. M. L. S. (2006). Percepção de alunos do ensino fundamental quanto ao clima de sala de aula para a criatividade. Psicologia em Estudo, 11, 513521.

Franco, M. L. P. B. (2005). Análise de conteúdo (2a ed.). Brasília, DF: Liber Livro.

Gomes, C. A. (2000). O ensino médio no Brasil: Ou a história do patinho feio recontada. Brasília, DF: Universa.

Lei No. 9394/96, de 20 de dezembro de 1996. (1996, 20 de dezembro de 1996). Estabelece as Diretrizes e Bases da Educação Nacional. Diário Oficial da União, seção 1.

Mariani, M. F. M., \& Alencar, E. M. L. S. (2005). Criatividade no trabalho docente segundo professores de história: Limites e possibilidades. Psicologia Escolar e Educacional, 9, 27-35.

Martínez, A. M. (1997). Criatividade, personalidade e educação. Campinas, SP: Papirus.

Martínez, A. M. (2002). A criatividade na escola: Três direções de trabalho. Linhas Críticas, 8, 189-206.

Martínez, A. M. (2006). Criatividade no trabalho pedagógico e criatividade na aprendizagem. In M. C. V. R. Tacca (Org.), Aprendizagem e trabalho pedagógico (pp. 6994). Campinas, SP: Alínea.

Ministério da Educação. (1999). Parâmetros Curriculares Nacionais: Ensino médio/bases legais. Brasília, DF: Ministério da Educação.

Ministério da Educação. (2004). Qualidade da educação: Uma nova leitura do desempenho dos estudantes da $3^{a}$ série do ensino médio. Brasília, DF: Ministério da Educação.

Miranda, S. (2005). Professor, não deixe a peteca cair! 63 ideias para aulas criativas ( $2 \mathrm{a}$ ed.). Campinas, SP: Papirus.

Morgan, S., \& Foster, J. (1999). Creativity in the classroom. Gifted Education International, 14, 29-43.
Nakano, T. C., \& Wechsler, S. M. (2007). Identificação e avaliação do talento criativo. In D. S. Fleith \& E. M. L. S. Alencar (Orgs.), Desenvolvimento de talentos e altas habilidades: Orientação a pais e professores (pp. 87-98). Porto Alegre: Artmed.

Oliveira, Z. M. F. (2007). Criatividade na formação do professor do curso de Letras. Dissertação de mestrado não publicada, Universidade Católica de Brasília, Brasília, DF.

Organização das Nações Unidas para Educação, Ciência e Cultura. (2003). Ensino médio no século XXI: Desafios, tendências e prioridades (Cadernos UNESCO Brasil. Série Educação, Vol. 9). Brasília, DF: Autor.

Quintián, C. A. G. (2006). La magia de los ambientes. In S. Torre \& V. Violant (Orgs.), Comprender y evaluar la creatividad (pp. 205-214). Málaga: Aljiber.

Renzulli, J. S. (1992). A general theory for the development of creative productivity in young people. In F. J. Mönks \& W. Peters (Orgs.), Talent for the future (pp. 51-72). Assen, Netherlands: Van Gorcum.

Ribeiro, R. A., \& Fleith, D. S. (2007). O estímulo à criatividade em cursos de licenciatura. Paidéia (Ribeirão Preto), 38, 413-416.

Santeiro, T. V., Santeiro, F. R. M., \& Andrade, I. (2004). Professor facilitador e inibidor da criatividade segundo universitários. Psicologia em Estudo, 9, 95-102.

Silva, C. J. (1994). Criatividade: Bem-me-quer, mal-mequer. In E. M. L. S. Alencar \& A. M. R. Virgolim (Orgs.), Criatividade: Expressão e desenvolvimento (pp. 73-95). Petrópolis, RJ: Vozes.

Silva, O. J., \& Alencar, E. M. L. S. (2003). Criatividade no ensino de Enfermagem: Enfoque triádico: Professor, aluno, currículo. Revista Brasileira de Enfermagem, 56, 610-614.

Souza, M. E., \& Alencar, E. M. L. S. (2006). O curso de pedagogia e as condições para o desenvolvimento da criatividade. Psicologia Escolar e Educacional, 10, 2130.

Wechsler, S. M. (2002a). Criatividade: Descobrindo e encorajando. Contribuições teóricas e práticas para as mais diversas áreas (3a ed.). Campinas, SP: Livro Pleno.

Wechsler, S. M. (2002b). Criatividade e desempenho escolar: Uma síntese necessária. Linhas Críticas, 8, 179-188.

Werlang, C. M. (2005). Expressividade e criatividade no processo educativo nos anos iniciais do ensino fundamental. Dissertação de mestrado não publicada, Universidade do Oeste de Santa Catarina, Joaçaba, SC. 
Janaina Maria Oliveira Almeida é Mestre em Educação pelo Programa de Pós-graduação em Educação da Universidade Católica de Brasília, Professora do Instituto de Ensino Superior Cenecista.

Eunice Maria Lima Soriano de Alencar é Ph.D. em Psicologia Educacional pela Purdue University, Professora dos Programas de Pós-Graduação em Educação e Psicologia da Universidade Católica de Brasília.

Recebido: 16/09/2008

$1^{a}$ revisão: $12 / 11 / 2008$

$2^{a}$ revisão: $19 / 03 / 2009$

$3^{a}$ revisão: 30/12/2009

Aceite final: 19/01/2010 